\title{
Material Hardship and Internal Locus of Control Over the Prevention of Child Obesity in Low-Income Hispanic Pregnant Women
}

\author{
Rachel S. Gross, MD, MS; Alan L. Mendelsohn, MD; Michelle B. Gross, MS, RD; \\ Roberta Scheinmann, MPH; Mary Jo Messito, MD
}

From the Department of Pediatrics (Dr R. Gross), Albert Einstein College of Medicine, Children's Hospital at Montefiore, Bronx, NY; Division of Developmental - Behavioral Pediatrics (Dr Mendelsohn), Division of General Pediatrics (Ms M. Gross and Dr Messito), New York University School of Medicine and Bellevue Hospital Center, New York, NY; and Research and Evaluation Unit (Ms Scheinmann), Public Health

Solutions, New York, NY

The authors have no conflicts of interest to disclose.

This work was presented in part as a platform presentation at the Pediatric Academic Societies meeting in Washington, DC on May 4, 2013 Address correspondence to Rachel S. Gross, MD, MS, Department of Pediatrics, Albert Einstein College of Medicine, Children's Hospital at Montefiore, 3444 Kossuth Ave, Bronx, NY 10467 (e-mail: rgross@ @ontefiore.org).

Received for publication September 30, 2015; accepted February 2, 2016.

\section{Abstract}

OBJECTIVE: To determine the relations between household material hardships and having a low internal locus of control over the prevention of child obesity in low-income Hispanic pregnant women.

METHODS: We performed a cross-sectional analysis of baseline data collected during a third trimester prenatal visit from women participating in the Starting Early Study, a randomized controlled trial to test the efficacy of a primary care-based family-centered early child obesity prevention intervention. Using multiple logistic regression analyses, we determined whether 4 domains of material hardship (food insecurity, difficulty paying bills, housing disrepair, neighborhood stress), considered individually and also cumulatively, were associated with having a low internal locus of control over the prevention of child obesity.

RESULTS: The sample included 559 low-income Hispanic pregnant women, with $60 \%$ having experienced at least 1 hardship. Food insecurity was independently associated with a low internal locus of control over the prevention of child obesity (adjusted odds ratio, 2.38; 95\% confidence interval, 1.50-3.77), controlling for other hardships and confounders. Experiencing a greater number of material hardships was associated in a dose-dependent relationship with an increased odds of having a low internal locus of control.

CoNCLUSIONS: Prenatal material hardships, in particular food insecurity, were associated with having a lower prenatal internal locus of control over the prevention of child obesity. Longitudinal follow-up of this cohort is needed to determine how relations between material hardships and having a low internal locus of control will ultimately affect infant feeding practices and child weight trajectories.

KEYwords: infant; locus of control; poverty; pregnancy; weight

Academic Pediatrics 2016; $\square: 1-7$

\section{WHAT'S NEW}

We found that prenatal material hardships are linked to a low internal locus of control over the prevention of child obesity. These findings link poverty-related challenges to prenatal attitudes that might ultimately increase obesity-promoting infant feeding practices and weight trajectories.

POVERTY-RELATED DISPARITIES IN early child obesity have significant public health implications, including adverse effects on child health ${ }^{1}$ and the increased risk of obesity across the life-course. ${ }^{2}$ Ethnic disparities also exist, with Hispanic children having the highest prevalence of overweight in the first 2 years of life compared with nonHispanic white and African American children. ${ }^{3}$ Research has identified modifiable maternal behaviors associated with child obesity risk during infancy, such as breast or formula feeding. ${ }^{4}$ An understanding of maternal characteristics related to these behaviors is important for the development of obesity prevention strategies. Because feeding intentions and attitudes are established during pregnancy and predict infant feeding behaviors, it is essential to identify the contributing characteristics that influence these attitudes during pregnancy. ${ }^{5}$

Internal locus of control, defined as one's sense of personal control over life outcomes, is a prenatal characteristic that might serve as an early antecedent of child obesity-promoting behaviors. ${ }^{6}$ Individuals with a low internal locus of control believe that they are not able to control their own life outcomes. Those with a more external locus of control believe that their life outcomes are controlled by powerful others, fate, or luck. With respect to health, beliefs that one's own actions lead to positive health outcomes is thought to motivate healthy 
behaviors. During pregnancy, the degree to which a woman perceives that she is responsible for the health of her fetus has been related to multiple prenatal health behaviors as well as intentions regarding postnatal behaviors. ${ }^{7-9}$ Specific to infant feeding, pregnant women who have higher internal locus of control with regard to fetal health are more likely to intend to breastfeed. ${ }^{10}$

Low internal locus of control might mediate multiple negative parenting and child health behaviors linked to living in poverty. ${ }^{11} \mathrm{~A}$ few studies have linked challenges associated with poverty, in particular household material hardships, to having a low internal locus of control. During pregnancy, food insecurity has been linked to beliefs in greater control by others or chance rather than themselves. ${ }^{12}$ The daily hassles and anxiety that commonly accompany poverty and high neighborhood deprivation have been related to lower self-perceived control. ${ }^{13,14}$ Furthermore, a broad body of evidence suggests that experiencing an increasing number of hardships has greater effects on child health and development. ${ }^{15,16}$

To our knowledge, no previous studies have comprehensively assessed whether individual material hardships during pregnancy, such as food insecurity, difficulties paying bills, housing disrepair, and neighborhood stress, as well as their cumulative effects, are associated with prenatal internal locus of control related to preventing child obesity. Therefore, we sought to understand how material hardships, considered individually and also cumulatively, are associated with prenatal internal locus of control over the prevention of child obesity (LOC-PCO) in low-income Hispanic pregnant women.

\section{METHODS}

\section{Study Design}

We performed a cross-sectional analysis of data from pregnant women participating in the Starting Early Study, a randomized controlled trial to test the efficacy of a primary care-based family-centered early child obesity prevention intervention. The Starting Early intervention was designed for low-income Hispanic families. It begins in the third trimester of pregnancy and continues until child age 3 years old. Data used in these analyses were collected between August 2012 and December 2014 before randomization during a baseline survey at a third trimester prenatal visit. Trained bilingual research staff conducted an interviewer-administered survey in either English or Spanish. This study was approved by the institutional review boards of New York University School of Medicine and the Albert Einstein College of Medicine, by Bellevue Hospital Center, and by the New York City Health and Hospitals Corporation. This study was registered on clinicaltrials.gov (NCT01541761).

\section{Study SAMPLe}

This study took place in the prenatal clinics of a large urban public hospital and an affiliated satellite neighborhood health center. Inclusion criteria were: 1) age $\geq 18$ years old, 2) self-identification as Hispanic/Latina, 3) fluent in English or Spanish, 4) singleton uncomplicated pregnancy, and 5) intention to receive prenatal and pediatric care at the study sites. Exclusion criteria were: significant medical or psychiatric illness, homelessness, substance abuse or severe fetal anomalies on ultrasound examination. At a prenatal visit between 28 and 32 weeks' gestational age, women were approached and assessed for eligibility. Women interested in participating signed written informed consent and completed baseline assessments.

\section{Assessments}

\section{INDEPENDENT VARIABLES}

Household food insecurity was assessed using the Core Food Security Module from the US Department of Agriculture $^{17}$ on the basis of a 12-month period that overlapped the pregnancy. Continuous scores were generated from 10 questions (Cronbach $\alpha=.53$ ) and dichotomized using recommended cut points. Women were classified as "food secure" if they reported no more than 2 foodinsecure conditions and "food insecure" if they reported 3 or more.

Difficulties paying bills was assessed using 2 questions from the Survey of Income and Program Participation $\left.(\mathrm{SIPP})^{18}: 1\right)$ "Have you had serious financial problems or been unable to pay monthly bills, rent, or mortgage during the past 12 months?"; 2) "Has there been a time when your household had service turned off by the gas or electric company, or the telephone company?" Continuous scores were generated on the basis of the sum of the responses $(\alpha=.53)$. A categorical variable was defined as a "yes" response to either of these questions.

Housing disrepair was measured using questions from the Survey of Income and Program Participation. ${ }^{18} \mathrm{We}$ asked women "Are any of the following conditions present in your home?" Responses included 1) a leaking roof or ceiling, 2) a toilet, hot water heater, or other plumbing that does not work, 3) broken windows, 4) exposed electric wires, 5) rats, mice, roaches, or other insects, 6) holes in floor (large enough to trip in), and 7) open cracks or holes in the walls or ceiling. Continuous scores were generated on the basis of the number of housing conditions experienced $(\alpha=.51)$. A categorical variable for housing disrepair was defined as a "yes" response to any of the housing conditions.

Neighborhood stress was measured using questions from the Pregnancy Risk Assessment Monitoring System. ${ }^{19}$ Mothers were asked: "Did you do any of the following things because you felt it was unsafe to leave or return to the neighborhood where you live?": 1) miss doctor or other appointments, 2) limit grocery or other shopping, and 3) stay with other family members or friends. Responses were on the basis of a 5-point Likert scale (never, almost never, sometimes, fairly often, and always). Continuous scores were generated from the sum of the 3 questions $(\alpha=.59)$. A categorical variable was defined as never versus ever experiencing neighborhood stress. 


\section{DEPENDENT VARIABLE}

Internal LOC-PCO was assessed using questions adapted from the Parental Health Belief Scale to measure sense of personal control over providing a healthy child diet and preventing child obesity. ${ }^{6}$ Women stated whether they agreed with the following 4 statements: 1) "I can do a lot of things to prevent my child from becoming overweight," 2) "There is nothing I can do to prevent my child from becoming overweight," 3) "I can do a lot to make sure my child has a healthy diet," and 4) "I can do a lot to make sure that my child has a healthy weight." Responses were on the basis of a 5-point Likert scale (strongly disagree, somewhat disagree, no opinion, somewhat agree, and strongly agree). A continuous score was generated from the sum of the 4 questions; each scored from 1 to 5 $(\alpha=.44)$. Question 2 was reverse coded. To minimize the effects of the responses being skewed, the variable was also dichotomized, with low internal LOC-PCO defined as the lowest quartile. ${ }^{20,21}$

\section{Additional Covariates}

Prenatal depressive symptoms were measured using the Patient Health Questionnaire- $9,{ }^{22}$ a validated tool used to measure symptoms in the past 2 weeks. Depressive symptoms (scale of 0-27) were dichotomized at recommended cut points with no symptoms (0-4) versus mild or greater depressive symptoms (5-27).

Other sociodemographic characteristics that were assessed included education (less than high school, high school or more), marital status (single, married), employment (nonworking, working), country of birth (non-USborn, US-born), and other children (first child, $\geq 1$ child). Prepregnancy body mass index (calculated as weight $[\mathrm{kg}] /$ height $\left[\mathrm{m}^{2}\right]$ ) was calculated using weight and height from medical record review and categorized as underweight $(<18.5)$, normal weight (18.5-24.9), overweight $(25-29.9)$, and obese $(\geq 30){ }^{23}$

\section{Statistical Analysis}

Data analyses were performed using SPSS statistical software version 18.0 (SPSS Inc, Chicago, Il). The distribution of the dependent variable, LOC-PCO, was left-skewed (skewness [standard error] $=-1.92[.10]$ ). We first performed bivariate analyses of the relationships between the individual material hardships (food insecurity, difficulty paying bills, housing disrepair, neighborhood stress) and internal LOC-PCO scores using the MannWhitney $U$ test. We next performed multiple linear and logistic regression analyses to explore independent associations between material hardships and LOC-PCO. Multiple linear regressions were performed using a log-transformation of LOC-PCO scores that had been reversed to account for left-skewing. ${ }^{24}$ Multiple logistic regressions were performed predicting LOC-PCO in the lowest quartile. Each of these regressions was performed using 2 models. Model 1 included all 4 individual material hardships entered simultaneously. Model 2 regressions further adjusted for potential covariates, including education, marital status, employment, country of birth, other children, prenatal depressive symptoms, and prepregnancy weight status. Next, individual hardships were summed to determine the total number of hardships experienced by each subject. Scores ranged from experiencing no hardship to experiencing 4 hardships. Multiple linear and logistic regression analyses were conducted to determine relationships between the number of hardships and the continuous internal LOC-PCO score and also the dichotomous low LOC-PCO variable respectively, using 'no hardship' as the reference group. Multiple regression analyses were also conducted using the total number of hardships as a predictor, to determine the adjusted odds ratio per increase in hardship.

\section{Results}

\section{Study SAMPLE}

Nine hundred thirty-three low-income Hispanic pregnant women were eligible for the Starting Early randomized controlled trial. Three hundred sixty-seven (39\%) of these women declined to participate, leaving 566 women who signed consent. Five hundred fifty-nine women completed baseline assessments before randomization and were included in these analyses. Most were non-USborn, with most from Mexico (46.0\%), Ecuador (15.6\%), and the Dominican Republic (5.7\%). In addition, 32.9\% had less than a high school education, $29.6 \%$ were single, and $34.9 \%$ reported depressive symptoms (Table 1). Material hardships were high, with $30.7 \%$ reporting food insecurity, $27.2 \%$ reporting difficulty paying bills, $33.5 \%$ reporting housing disrepair, and $8.6 \%$ reporting neighborhood stress. The mean (SD) internal LOC-PCO score was 19.0 (1.66), ranging from 12 to 20 . The bottom quartile represented scores between 12 and 18 (24\%). Less education and prenatal depressive symptoms were associated with lower internal LOC-PCO scores (Table 1).

\section{Material Hardship and Locus of Control}

In unadjusted bivariate analyses (Table 2), women with food insecurity had lower mean LOC-PCO scores (18.52 vs 19.21; $P<.001)$ and increased likelihood of low LOC-PCO compared with mothers with food security (38.1\% vs $17.7 \% ; P<.001)$. Women with neighborhood stress had lower mean LOC-PCO scores (18.46 vs 19.05; $P=.003)$ and increased likelihood of low LOC-PCO compared with mothers without neighborhood stress $(37.5 \%$ vs $22.3 \% ; P<.03)$. Women with housing disrepair had lower mean LOC-PCO scores ( 18.83 vs $19.09 ; P=.07)$ and increased likelihood of low LOC-PCO compared with mothers without housing disrepair (29.4\% vs $20.7 \%$; $P<.03)$. Difficulties paying bills was not significantly associated with LOC-PCO.

Using multiple linear regression models with all 4 hardships entered simultaneously, food insecurity was found to be independently associated with having a lower internal LOC-PCO in unadjusted $(\beta=.20 ; 95 \%$ confidence interval $[\mathrm{CI}], .07-.17$ [model 1]) and adjusted $(\beta=.16 ; 95 \%$ CI, .04-.15 [model 2]) analyses 
Table 1. Family Characteristics and Prenatal Internal LOC-PCO

\begin{tabular}{|c|c|c|c|}
\hline Characteristics & Study Sample $(\mathrm{n}=559), \mathrm{n}(\%)$ & Internal LOC-PCO, ${ }^{*}$ Mean (SD) & $P$ \\
\hline \multicolumn{4}{|l|}{ US born } \\
\hline Yes & $117(20.9)$ & $19.26(1.49)$ & \multirow[t]{2}{*}{.05} \\
\hline No & $442(79.1)$ & $18.94(1.70)$ & \\
\hline \multicolumn{4}{|c|}{ Education, less than high school } \\
\hline Yes & $184(32.9)$ & $18.56(1.87)$ & \multirow[t]{2}{*}{$<.001$} \\
\hline No & $375(67.1)$ & $19.22(1.50)$ & \\
\hline \multicolumn{4}{|l|}{ Marital status, single } \\
\hline Yes & 165 (29.6) & $18.81(1.75)$ & \multirow[t]{2}{*}{.06} \\
\hline No & $393(70.4)$ & $19.08(1.61)$ & \\
\hline \multicolumn{4}{|l|}{ Working } \\
\hline Yes & $143(25.6)$ & $19.13(1.69)$ & \multirow[t]{2}{*}{.08} \\
\hline No & $416(74.4)$ & $18.96(1.65)$ & \\
\hline \multicolumn{4}{|l|}{ First child } \\
\hline Yes & $212(38.0)$ & $19.12(1.61)$ & \multirow[t]{2}{*}{.08} \\
\hline No & $347(62.1)$ & $18.93(1.68)$ & \\
\hline \multicolumn{4}{|l|}{ Depressive symptoms } \\
\hline Yes & 195 (34.9) & $18.84(1.65)$ & \multirow[t]{2}{*}{.02} \\
\hline No & $363(65.1)$ & $19.09(1.66)$ & \\
\hline \multicolumn{4}{|l|}{ Prepregnancy BMI $\geq 25$} \\
\hline Yes & $344(61.5)$ & $18.97(1.67)$ & \multirow[t]{2}{*}{.41} \\
\hline No & $215(38.5)$ & $19.07(1.64)$ & \\
\hline
\end{tabular}

$\mathrm{BMI}$ indicates body mass index; LOC-PCO, locus of control over the prevention of child obesity.

*Internal LOC-PCO scores were based the sum of 4 questions with scores ranging from 4 to 20 . Higher scores represent higher internal locus of control.

(Table 2). Similar results were found using logistic regression models with the dichotomous LOC-PCO outcome, in which food insecurity was independently associated with having a low internal LOC-PCO in unadjusted (odds ratio $=2.75 ; 95 \%$ CI, 1.77-4.27 [model 1]) and adjusted (adjusted odds ratio $[\mathrm{AOR}]=2.38 ; 95 \% \mathrm{CI}$, 1.50-3.77 [model 2]) analyses.

\section{Cumulative Number of Hardships}

In multiple linear regression models, experiencing 3 to 4 hardships was associated with having a lower internal LOC-PCO score compared with having no hardships in unadjusted ( $\beta=.16 ; 95 \% \mathrm{CI}, .07-.22$ [model 1]) and adjusted $(\beta=.13 ; 95 \%$ CI, .03-.20 [model 2]) analyses (Table 3). Experiencing 1 to 2 hardships was associated with having lower internal LOC-PCO scores, but these findings were not statistically significant. Using logistic regression with the dichotomous LOC-PCO outcome, experiencing a greater number of hardships was related in a dosedependent relationship, using "no hardship" as the reference. Families with 1 hardship had an AOR of having a low LOC-PCO of 1.74 (95\% CI, 1.04-2.93), and families experiencing 3 to 4 hardships had an AOR of 2.70 (95\% CI, 1.35-5.41), compared with having no hardships. Using multiple logistic regression, including the number of hardships as a predictor variable, each additional hardship was associated with an AOR of 1.42 (95\% CI, 1.16-1.74) for predicting a low internal LOC-PCO.

\section{Discussion}

In this study of low-income, Hispanic pregnant women, we found that material hardship was associated with having a lower internal locus of control related to the prevention of child obesity. Pregnant women who experienced multiple hardships showed a dose-dependent relationship between the increasing number of hardships and having a low internal locus of control. Food insecurity was found to be the hardship with the strongest association. These results suggest that prenatal material hardships might play an important role in reducing internal locus of control over preventing child obesity.

Living in poverty significantly increases the risk of obesity beginning in infancy and its sustained effects throughout the life course. ${ }^{3}$ Socioeconomic disparities in the rates of early child obesity exist, with children from low-income households most affected. ${ }^{3}$ Despite the awareness of these disparities, the mechanism through which poverty affects child obesity remains unclear, hindering efforts to develop effective obesity prevention strategies for low-income families. Understanding the early antecedents of parent behaviors related to early child obesity is essential to developing prevention strategies. Our findings suggest that material hardships function as potentially important early antecedents.

Because material hardships commonly occur in clusters rather than as individual occurrences, it is important to consider their cumulative effects. Our finding that experiencing multiple prenatal hardships showed a dosedependent relationship with having a low internal locus of control, corresponds well with evidence documenting the negative effects of cumulative risks. Studies of cumulative risks, such as adverse childhood experiences, have reported that more risks result in a stronger, dose-dependent relationship with numerous health, social, and behavioral problems. ${ }^{15,16,25,26}$ Cumulative material hardships, such as having housing instability and food insecurity, have been associated with poor child health, growth, and development, ${ }^{16}$ and have been shown to mediate the relationship between poverty and child weight. ${ }^{27}$ 
Table 2. Relationship Between Household Material Hardships and Internal LOC-PCO

\begin{tabular}{|c|c|c|c|c|c|c|}
\hline \multirow[b]{2}{*}{ Material Hardship } & \multirow[b]{2}{*}{ Mean (SD) } & \multirow[b]{2}{*}{$P$} & \multicolumn{2}{|c|}{ Model $1^{*}$} & \multicolumn{2}{|c|}{ Model 2† } \\
\hline & & & $\beta$ & $95 \% \mathrm{Cl}$ & $\beta$ & $95 \% \mathrm{Cl}$ \\
\hline \multicolumn{7}{|c|}{ Internal LOC (continuous score) } \\
\hline Food insecure & & $<.001$ & .20 & .07 to .17 & .16 & .04 to .15 \\
\hline Yes & $18.52(1.85)$ & & & & & \\
\hline No & $19.21(1.54)$ & & & & & \\
\hline Difficulty paying bills & & .41 & -.04 & -.08 to .03 & -.04 & -.08 to .03 \\
\hline Yes & $18.88(1.78)$ & & & & & \\
\hline No & $19.05(1.61)$ & & & & & \\
\hline Housing disrepair & & .07 & .06 & -.02 to .08 & .05 & -.02 to .08 \\
\hline Yes & $18.83(1.76)$ & & & & & \\
\hline No & 19.09 (1.60) & & & & & \\
\hline Neighborhood stress & & .003 & .09 & .003 to .17 & .08 & -.01 to .16 \\
\hline Yes & $18.46(1.86)$ & & & & & \\
\hline \multirow[t]{2}{*}{ No } & $19.05(1.63)$ & & & & & \\
\hline & Low LOC, n (\%) & & OR & & AOR & \\
\hline \multicolumn{7}{|c|}{ Low internal LOC (categorical variable) } \\
\hline Food insecure & & $<.001$ & 2.75 & $1.77-4.27$ & 2.38 & $1.50-3.77$ \\
\hline Yes & $64(38.1)$ & & & & & \\
\hline No & $67(17.7)$ & & & & & \\
\hline Difficulty paying bills & & .18 & .82 & $.51-1.32$ & .79 & $.48-1.30$ \\
\hline Yes & $42(27.6)$ & & & & & \\
\hline No & $90(22.1)$ & & & & & \\
\hline Housing disrepair & & .03 & 1.45 & $.95-2.21$ & 1.43 & $.92-2.22$ \\
\hline Yes & $55(29.4)$ & & & & & \\
\hline No & $77(20.7)$ & & & & & \\
\hline Neighborhood stress & & .03 & 1.75 & $.90-3.40$ & 1.60 & $.80-3.18$ \\
\hline Yes & 18 (37.5) & & & & & \\
\hline No & $114(22.3)$ & & & & & \\
\hline
\end{tabular}

AOR indicates adjusted odds ratio; BMI, body mass index; Cl, confidence interval; LOC, locus of control; LOC-PCO, locus of control over the prevention of child obesity; and OR, odds ratio.

*Model 1 uses regression models with all 4 material hardships (food insecurity, difficulties paying bills, housing disrepair, and neighborhood stress) entered simultaneously into the model.

†Model 2 uses regression models with all 4 material hardships entered simultaneously into the model as well as additional potential confounders including US-born, maternal education, marital status, working status, first child, depressive symptoms, and prepregnancy BMI $\geq 25$.

$\ddagger$ Multiple linear regressions were performed using a log-transformation of LOC-PCO scores that had been reversed to account for left skewing. Higher $\beta$ values represent lower LOC-PCO scores.

Of the 4 material hardships studied, food insecurity was found to be the most strongly associated with prenatal locus of control regarding child obesity prevention. Because food insecurity is the only food-specific hardship studied, it is not surprising that it is most related to attitudes about infant weight. Food insecurity has been previously associated with maternal feeding styles and attitudes that increase obesogenic feeding practices and child obesity. A study of low-income Hispanic mothers with infants in the first 6 months of life showed that food-insecure mothers are more likely to exhibit controlling feeding styles, mediated by concern for the infant becoming overweight. ${ }^{28}$ Food insecure families also have decreased parental selfefficacy to make fruit and vegetables available for children. ${ }^{29}$ Our current findings expand on these previous studies by showing that food insecurity is related to important infant feeding attitudes during pregnancy.

Studies have shown that pregnancy, which often represents a unique time of transition for a family, can make women vulnerable for increased material hardship. . $^{12,30,31}$ During pregnancy, increasing nutritional demands, shifts in household responsibilities, and changes in employment have been shown to change the family budget and require families to adjust to a lower income. A qualitative study of pregnant Latina women reported high levels of stress about not having enough money to buy nutritious foods to feed themselves, their unborn baby, and their family. ${ }^{32}$ Our findings further document that material hardships commonly occur during this vulnerable period, with approximately $60 \%$ of our sample experiencing at least 1 hardship. These findings are concerning because prenatal stressors are likely to influence attitudes strongly related to later parenting practices and have long-term effects on child outcomes. ${ }^{5,33}$ Our findings support the need for 2 generational obesity prevention strategies beginning during pregnancy.

Because prenatal attitudes are strongly related to later parenting practices, our findings have clinical implications. Prenatal internal locus of control might be a critical antecedent of obesity-promoting feeding behaviors during infancy in low-income families experiencing material hardship. This corresponds with studies that reported that higher internal locus of control during pregnancy is associated with positive prenatal health behaviors and breastfeeding intentions. ${ }^{7-9}$ Pregnant women with a greater internal locus of control regarding fetal health show better 
Table 3. Cumulative Material Hardship and Internal LOC Over the Prevention of Child Obesity

\begin{tabular}{|c|c|c|c|c|c|c|}
\hline \multirow[b]{2}{*}{ Cumulative Hardship } & \multirow[b]{2}{*}{ Total, n (\%) } & \multirow[b]{2}{*}{ Mean (SD) } & \multicolumn{2}{|c|}{ Model $1^{*}$} & \multicolumn{2}{|c|}{ Model $2 \dagger$} \\
\hline & & & $\beta$ & $95 \% \mathrm{Cl}$ & $\beta$ & $95 \% \mathrm{Cl}$ \\
\hline \multicolumn{7}{|c|}{ Internal LOC (continuous score)† } \\
\hline No hardship & $218(39.9)$ & $19.22(1.64)$ & REF & & REF & \\
\hline 1 Hardship & 180 (32.9) & $19.04(1.50)$ & .07 & -.01 to .09 & .05 & -.03 to .08 \\
\hline 2 Hardships & $91(16.6)$ & $18.79(1.64)$ & .11 & .02 to .15 & .09 & -.004 to .13 \\
\hline \multirow[t]{2}{*}{ 3-4 Hardships } & $58(10.6)$ & $18.36(2.13)$ & .16 & .07 to .22 & .13 & .03 to .20 \\
\hline & & With Low LOC n (\%) & OR & & AOR & \\
\hline \multicolumn{7}{|c|}{ Low internal LOC (categorical variable) } \\
\hline No hardship & 218 (39.9) & $33(15.1)$ & REF & & REF & \\
\hline 1 Hardship & $180(32.9)$ & $46(25.6)$ & 1.92 & $1.17-3.17$ & 1.74 & $1.04-2.93$ \\
\hline 2 Hardships & 91 (16.6) & 30 (33.0) & 2.75 & $1.56-4.88$ & 2.40 & $1.30-4.42$ \\
\hline 3-4 Hardships & 58 (10.6) & $22(37.9)$ & 3.42 & $1.80-6.54$ & 2.70 & $1.35-5.41$ \\
\hline \multicolumn{7}{|c|}{$\begin{array}{l}\text { AOR indicates adjusted odds ratio; BMI, body mass index; } \mathrm{Cl} \text {, confidence interval; LOC, locus of control; LOC-PCO, locus of control over } \\
\text { he prevention of child obesity; OR, odds ratio; and REF, reference. } \\
\text { *Model } 1 \text { uses regression models with number of hardships entered simultaneously into model, using "no hardship" as the reference group. } \\
\text { †Model } 2 \text { uses regression models with number of hardships entered simultaneously into model as well as additional potential confounders } \\
\text { ncluding US-born, maternal education, marital status, working status, first child, depressive symptoms, and prepregnancy BMI } \geq 25 \text {, using } \\
\text { "no hardship" as the reference group. } \\
\text { †Multiple linear regressions were performed using a log-transformation of LOC-PCO scores that had been reversed to account for left } \\
\text { skewing. Higher } \beta \text { values represent lower LOC-PCO scores. }\end{array}$} \\
\hline
\end{tabular}

adherence with limiting caffeine, ${ }^{7}$ avoidance of smoking, participation in physical activity, ${ }^{8}$ and health informationseeking. ${ }^{9}$ Breastfeeding high self-efficacy and intentions during pregnancy are known to predict higher breastfeeding rates. ${ }^{5,34}$ Later in childhood, an external parental locus of control has been associated with unhealthier child diets. ${ }^{35}$ Further longitudinal study is needed to understand how prenatal internal locus of control will affect maternal-child feeding behaviors and child weight trajectories.

This study has several limitations. First, our sample was a cohort of low-income Hispanic women, which might limit generalizability to all pregnant women. Although the study controlled for a range of potential confounders, additional family and community level confounders might exist. Second, because no measure of locus of control regarding the prevention of child obesity existed, it was necessary to adapt questions from a preexisting healthrelated parental locus of control questionnaire validated in a Hispanic, Puerto Rican population. ${ }^{6}$ Using this adapted measure, we found that internal LOC-PCO scores were generally high in our sample of pregnant women who originated primarily from Mexico and Ecuador. Because perceived locus of control was assessed during pregnancy, some women might have had difficulty with questions that were oriented toward after the birth of the baby, and therefore hypothetical. In addition, it remains unclear how the mothers interpreted the terms "overweight" and "healthy diet." It is possible that their interpretation of these terms could differ on the basis of experiencing food insecurity or other hardships. Although locus of control is believed to be a complex, multidimensional construct, we were only able to study internal locus of control. In particular, we did not assess external locus of control, including beliefs that the prevention of child obesity is controlled by powerful others, such as medical professionals, or by fate, chance, or luck. We also did not assess other healthspecific aspects of locus of control, and it is possible that our findings could be due to overall locus of control orientation rather than obesity-related locus of control. Furthermore, the cross-sectional design prevents making conclusions that material hardship directly causes a low internal locus of control. The cross-sectional design during pregnancy prevents us at this time from studying effects on subsequent feeding practices or obesity. Following the cohort longitudinally throughout the child's first 3 years of life will help to determine how material hardship and prenatal locus of control regarding preventing child obesity will affect parenting behaviors and ultimately child weight status.

\section{Conclusions}

Findings suggest that prenatal material hardships, in particular food insecurity, are associated with a mother's belief in her own role in promoting healthy child diet and growth. Experiencing multiple material hardships showed a dose-dependent relationship. Further work is needed to understand how the relationship between prenatal material hardships and a low internal locus of control affects child feeding practices and child growth trajectories. Future studies need to determine if interventions should aim to improve internal locus of control or need to focus further downstream on decreasing material hardships during pregnancy. Because low-income pregnant women experience high rates of material hardship, screening for these hardships during pregnancy might be critical to early intervention. These findings also highlight that early child obesity prevention beginning in pregnancy will likely need to combine health care programs with public health efforts to address the complex, multifactorial challenges faced by families in poverty. Such efforts could include coordinating with population-based programs, such as the 
Supplemental Nutrition Assistance Program for Women, Infant and Children, and affordable housing assistance programs. These efforts to reduce health disparities might need to target material hardship during pregnancy to affect prenatal attitudes that influence parenting behaviors associated with child obesity.

\section{ACKNOWLEDGMENTS}

We thank the Starting Early Program staff who contributed to this project, including Ana Blanco, MS, RD, Lisa Lanza, RD, Janneth Bancayan, BA, Kenny Diaz, BA, Stephanie Gonzalez, BA, Christopher Ramirez, BA, and Jessica Rivera, BS.

Financial disclosure: This work was supported by the National Institute of Food and Agriculture, US Department of Agriculture, award number 2011-68001-30207, and the National Institutes of Health/National Institute of Child Health and Human Development through a K23 Mentored Patient-Oriented Research Career Development Award (5K23HD081077-02; PI Gross).

Previous presentations: This work was presented in part as a platform presentation at the Pediatric Academic Societies meeting in Washington, DC on May 4, 2013.

\section{REFERENCES}

1. Reilly JJ, Armstrong J, Dorosty AR, et al. Early life risk factors for obesity in childhood: cohort study. BMJ. 2005;330:1357.

2. Nader PR, O'Brien M, Houts R, et al. Identifying risk for obesity in early childhood. Pediatrics. 2006;118:e594-e601.

3. Ogden CL, Carroll MD, Kit BK, et al. Prevalence of childhood and adult obesity in the United States, 2011-2012. JAMA. 2014;311: 806-814.

4. McGuire S. Institute of Medicine (IOM) early childhood obesity prevention policies. Adv Nutr (Bethesda). 2012;3:56-57.

5. Stuebe AM, Bonuck K. What predicts intent to breastfeed exclusively? Breastfeeding knowledge, attitudes, and beliefs in a diverse urban population. Breastfeed Med. 2011;6:413-420.

6. Pachter LM, Sheehan J, Cloutier MM. Factor and subscale structure of a parental health locus of control instrument (parental health beliefs scales) for use in a mainland united states Puerto Rican community. Soc Sci Med. 2000;50:715-721.

7. Labs SM, Wurtele SK. Fetal health locus of control scale: Development and validation. J Consult Clin Psychol. 1986;54:814-819.

8. Clarke PE, Gross H. Women's behaviour, beliefs and information sources about physical exercise in pregnancy. Midwifery. 2004;20: 133-141.

9. Shieh C, Broome ME, Stump TE. Factors associated with health information-seeking in low-income pregnant women. Womens Health. 2010;50:426-442.

10. Haslam C, Lawrence W, Haefeli K. Intention to breastfeed and other important health-related behaviour and beliefs during pregnancy. Fam Pract. 2003;20:528-530.

11. Wardle J, Steptoe A. Socioeconomic differences in attitudes and beliefs about healthy lifestyles. J Epidemiol Community Health. 2003 ; 57:440-443.

12. Laraia BA, Siega-Riz AM, Gundersen C, et al. Psychosocial factors and socioeconomic indicators are associated with household food insecurity among pregnant women. J Nutr. 2006;136:177-182.

13. Poortinga W, Dunstan FD, Fone DL. Health locus of control beliefs and socio-economic differences in self-rated health. Prev Med. $2008 ; 46: 374-380$

14. Ryon HS, Gleason ME. The role of locus of control in daily life. Pers Soc Psychol Bull. 2014;40:121-131.

15. Frank DA, Casey PH, Black MM, et al. Cumulative hardship and wellness of low-income, young children: multisite surveillance study. Pediatrics. 2010;125:e1115-e1123.
16. Cutts DB, Meyers AF, Black MM, et al. US housing insecurity and the health of very young children. Am J Public Health. 2011;101: 1508-1514.

17. Bickel G, Nord M, Price C, et al. Guide to Measuring Household Food Security, Revised 2000. Alexandria, Va: US Department of Agriculture, Food and Nutrition Service; 2000.

18. US Department of Commerce, Bureau of the Census. Survey of Income and Program Participation (SIPP) 1993 Panel, Longitudinal File. ICPSR Version: US Department of Commerce, Bureau of the Census Washington, DC: 1997.

19. Shulman HB, Gilbert BC, Msphbrenda CG, et al. The pregnancy risk assessment monitoring system (PRAMS): Current methods and evaluation of 2001 response rates. Public Health Rep. 2006;121:74-83.

20. Libert Y, Janne P, Razavi D, et al. Impact of medical specialists' locus of control on communication skills in oncological interviews. Br J Cancer. 2003;88:502-509.

21. Lekfuangfu WN, Cornaglia F, Powdthavee N, et al. Locus of control and its intergenerational implications for early childhood skill formation. Institute for the Study of Labor Discussion Paper No. 8487. Available at: http://ftp.iza.org/dp8487.pdf. Accessed December 21, 2015.

22. Kroenke K, Spitzer RL, Williams JB. The PHQ-9: validity of a brief depression severity measure. J Gen Intern Med. 2001;16:606-613.

23. Kuczmarski RJ, Carroll MD, Flegal KM, et al. Varying body mass index cutoff points to describe overweight prevalence among U.S adults: NHANES III (1988 to 1994). Obes Res. 1997;5:542-548.

24. Tabachnick BG, Fidell LS. Using Multivariate Statistics. 5th ed. Boston, MA: Allyn and Bacon; 2007.

25. Felitti VJ, Anda RF, Nordenberg D, et al. Relationship of childhood abuse and household dysfunction to many of the leading causes of death in adults. The Adverse Childhood Experiences (ACE) study. Am J Prev Med. 1998;14:245-258.

26. Shonkoff JP, Garner AS, Committee on Psychosocial Aspects of Child and Family Health, Committee on Early Childhood, Adoption, and Dependent Care, Section on Developmental and Behavioral Pediatrics. The lifelong effects of early childhood adversity and toxic stress. Pediatrics. 2012;129:e232-e246.

27. Wells NM, Evans GW, Beavis A, et al. Early childhood poverty, cumulative risk exposure, and body mass index trajectories through young adulthood. Am J Public Health. 2010;100:2507-2512.

28. Gross RS, Mendelsohn AL, Fierman AH, et al. Food insecurity and obesogenic maternal infant feeding styles and practices in lowincome families. Pediatrics. 2012;130:254-261.

29. Hilmers A, Cullen K, Moore C, et al. Exploring the association between household food insecurity, parental self-efficacy, and fruit and vegetable parenting practices among parents of 5- to 8-year-old overweight children. Available at: http://digitalcommons.library. tmc.edu/childrenatrisk/vol3/iss1/5. Assessed March 9, 2015.

30. Braveman P, Marchi K, Egerter S, et al. Poverty, near-poverty, and hardship around the time of pregnancy. Matern Child Health J. 2010;14:20-35.

31. Ivers LC, Cullen KA. Food insecurity: special considerations for women. Am J Clin Nutr. 2011;94:1740S-1744S.

32. Hromi-Fiedler A, Bermúdez-Millán A, Segura-Pérez S, et al. Adaptation of the US household food security survey module for low-income pregnant Latinas: qualitative phase. J Hunger Environ Nutr. 2009;4: 62-80.

33. Berkule SB, Dreyer BP, Huberman HS, et al. Attitudes about shared reading among at-risk mothers of newborn babies. Ambul Pediatr 2007;7:45-50.

34. Colaizy T, Saftlas A, Morriss F. Maternal intention to breastfeed and breastfeeding outcomes in term and preterm infants: PRAMS 2000-2003. Public Health Nutr. 2012;15:702-710.

35. Ystrom E, Barker M, Vollrath ME. Impact of mothers' negative affectivity, parental locus of control and child-feeding practices on dietary patterns of 3-year-old children: the MoBa cohort study. Matern Child Nutr. 2012;8:103-114. 